\title{
The Effect of Melissa officinalis Extract on Streptozotocin-Induced Diabetes in Rats: A Stereological Study on Pancreatic Islets and Beta-cells
}

\author{
Soheil Ashkani-Esfahani ${ }^{1,2}(\mathbb{D})$, Alireza Ebrahimi ${ }^{2}(\mathbb{D})$, Maryam Bahmani Jahromi ${ }^{2}(\mathbb{D})$, Elham Nadimi ${ }^{3}(\mathbb{D})$ \\ Hossein Arabzadeh 2 (D), Mohammad Hassan Jalalpour 2 (D), Ali Ghasemnezhad 2 (D), \\ Sedigheh Ebrahimi ${ }^{*}$ in \\ 1. Dept. of Orthopaedic Surgery, Massachusetts General Hospital, Harvard Medical School, Boston, Massachusetts, USA \\ 2. Student Research Committee, Shiraz University of Medical Sciences, Shiraz, Iran \\ 3. Stereology Research Center, Shiraz University of Medical Sciences, Shiraz, Iran \\ 4. Dept. of Medical Ethics, Shiraz University of Medical Sciences, Shiraz, Iran
}

\begin{tabular}{l}
\hline Article Info \\
\hline dof $\mathbf{1 0 . 3 0 6 9 9 / j a m b s . 2 9 . 1 3 2 . 1}$ \\
\hline \begin{tabular}{l} 
Received: $2020 / 06 / 16 ;$ \\
Accepted: $2020 / 08 / 12 ;$ \\
Published Online: 14 Nov 2020 \\
\hline Use your device to scan and read the \\
article online
\end{tabular} \\
\hline
\end{tabular}

Corresponding Information: Sedigheh Ebrahimi, Dept. of Medical Ethics, Shiraz University of Medical Sciences, Shiraz, Iran

E-Mail: sedighebrahimi@gmail.com

\begin{abstract}
Background \& Objective: Melissa officinalis (MO) was shown to possess antioxidant and anti-inflammatory properties and is traditionally believed to have antihyperglycemic effects. This study aims to evaluate the protective effects of MO on streptozotocin (STZ) induced pancreatic damage and thereupon diabetes in rats.

Materials \& Methods: To induce diabetes mellitus (DM) in rats, STZ (60 mg/kg) was injected intraperitoneally. Forty eight rats were randomly divided into four groups: control 1 (C1) consisted of healthy rats, control 2 (C2) consisted of non-treated diabetic rats, and treatment groups 1 and 2 (T1, T2) were the diabetics orally treated with 150 and $300 \mathrm{mg} / \mathrm{kg}$ MO for 14 days, respectively. After euthanizing the animals, their pancreases were extracted and sent for stereological evaluations. Volume density (Vv; \%), the absolute volume of the islets $\left(\mathrm{mm}^{3}\right)$, numerical density of beta cells (Nv; per $\left.\mathrm{mm}^{3}\right)$, and their total number $\left(\times 10^{6}\right)$, were measured. P-value $<0.05$ was considered as statistically significant.
\end{abstract}

Results: The treatment groups showed significant improvements in volume density and total volume of the islets as well as the numerical density and the total number of the beta cells $(P<0.001)$. The treatment groups also had significantly lower blood sugar compared to the untreated group $(P=0.008)$.

Conclusion: According to our results, MO has shown promising effects on the pancreatic beta cells against toxic chemicals such as STZ. However, further studies are needed to examine the beneficial effects and possible adverse effects of MO in laboratory models and also in humans.

Keywords: Beta-cells, Diabetes mellitus, Langerhans Islets, Melissa officinalis, Rats, Stereology

\section{Introduction}

The prevalence of diabetes mellitus (DM) is increasing because of population growth, aging, urbanization, the growing frequency of obesity, and physical inactivity. Previous studies highlighted that the number of patients with diabetes will approximately be doubled between 2000 and 2030 (1). Impaired glucose metabolism and insulin signaling pathways increase the oxidative stress in general hemostasis resulting in long-term complications of DM (2). Moreover, oxidative stress may also have a role in the pathogenesis of DM by increasing insulin resistance or decreasing insulin secretion (3). Therefore, the administration of antioxidative agents might improve or even prevent the disease. The current therapeutic guidelines for DM include dietary and lifestyle modifications, and administration of oral hypoglycemic agents and insulin (4).
Considering the complementary and alternative medicine (CAM) therapies for DM, several methods have been under investigation including acupuncture, hot tub therapy, biofeedback, homeopathy, administration of medicinal herbs, and nutritional supplementation $(4,5)$. Some of these therapies have been shown to improve glycemic control; however, the clinical effectiveness and safety of many of them are yet to be distinguished. The present evidence suggests that the consumption of vitamin-C, vitamin-E, tocopherols, tocotrienols, carotenoids besides, a diet high in vegetables and fruits could protect patients against DM (6-9).

Over 400 medicinal plants were introduced as a treatment for diabetes; however, a small number of these were clinically approved (10). In this regard, it is worth 
mentioning that the development of Metformin was based on Galega officinalis, which is rich in hypoglycemic agent, Guanidine $(10,11)$. Melissa officinalis (MO), also known as lemon balm, is a medicinal plant from the family of Lamiaceae that has been traditionally used as a medicine for several diseases including DM. This plant originally comes from the Eastern Mediterranean region and has been widely recommended by ethnopharmacy, especially the literature of middle-eastern regions (12). Previous reports mentioned that MO has antiviral, antimicrobial, antispasmodic, diuretic, sedative, and antioxidant properties (13, 14). Moreover, prior animal studies showed that the agent might have anti-diabetic, antinociceptive, and lipid-regulating influences $(15,16)$.

As mentioned above, oxidative stress may play a role in the pathophysiology of DM and diabetic sequelae. Therefore, the appropriate use of medicinal plants with high antioxidant potentials might prevent DM or improve symptoms by inhibiting oxidation chain reactions (3). Besides, MO has been traditionally used as a treatment for diabetes and consists of several antioxidative agents such as Rosmarinic acid and Quercitrin (17). In this study, we used stereological and histomorphometric methods to examine the Streptozotocin (STZ) induced injuries to the pancreatic beta cells and Langerhans islets to evaluate the protective effects of MO in this model of experimental diabetes in rats.

\section{Materials and Methods}

\section{Extracting plant material}

The plant was provided from Yasuj, Kohgiluyeh and Boyerahmad province in Southwestern Iran (Herbarium no: 13131). The process was supervised by the research center of agriculture and natural sources of Yasuj University of Medical Sciences, Yasuj, Iran. MO leaves were sterilized using ethanol $70 \%$ to reduce any possible chemical or microbiological contamination and dried at $50^{\circ} \mathrm{C}$ in shade. Then, 120 grams of dried leaves were ground into powder. The powder was mixed with $600 \mathrm{ml}$ of ethylic-water (7:3) in Soxhlet extractor for 72 hours; then, it was refrigerated at $3{ }^{\circ} \mathrm{C}$ for three days. After evaporation, a MO extract with a $16 \%$ concentration was obtained and kept at $-18^{\circ} \mathrm{C}$ until consumption.

\section{Streptozotocin administration and hyperglycemia induction}

STZ (Sigma-Aldrich ${ }^{\circledR}$, Steinheim, Germany) was intraperitoneally injected to the rats by a dosage of 60 $\mathrm{mg} / \mathrm{kg}$ of the body weight after 8 hours of overnight fasting. The strategy was designed according to a previous investigation, which showed the doses could elevate fasting blood glucose (FBS) to more than 300 $\mathrm{mg} / \mathrm{dl}$ in 8 out of 10 rats (18). Thereafter, FBS was daily monitored by a Glucometer (Rightest GM110, Bionime $^{\mathrm{TM}}$, Switzerland); a value higher than $300 \mathrm{mg} / \mathrm{dl}$ was considered as diabetic (18).

\section{Animal models}

Forty eight male adult normoglycemic rats (SpragueDawley) weighing $230 \pm 20$ grams which were kept in cages, were divided into 4 groups $(n=12)$ in a random manner. Free access to sufficient food and water and a temperature of $24 \pm 2^{\circ} \mathrm{C}$ plus 12-hour dark/light cycles were provided. The research protocol was approved by the institutional research board (IRB) of Shiraz University of Medical Sciences, Shiraz, Iran.

The first group was designed to be non-diabetic controls $(\mathrm{C} 1)$ and merely received $1 \mathrm{cc}$ of distilled water per oral (PO) every day. The second control group (C2) was STZ-induced diabetics with no treatment and received distilled water $\mathrm{PO}$ daily from day one. Treatment group 1 (T1) consisted of diabetics that received $150 \mathrm{mg} / \mathrm{kg}$ body weight $\mathrm{MO}$ extract solved in distilled water, with a total volume of $1 \mathrm{~mL}$, from the first day for 14 days PO. The second treatment group (T2) received a $300 \mathrm{mg} / \mathrm{kg} \mathrm{MO}$ extract solved in distilled water $(1 \mathrm{~mL})$ daily for 14 days. MO doses were picked according to a previous pilot study, in which the lowest doses with the best effects were chosen and STZ was administered 7 days after starting the treatments (18).

\section{Stereological study}

Before euthanizing the models, to examine if there is any difference between the investigated clusters, the body weights of the rats were measured. On day 14, after Ether-induced anesthesia, rats were killed by cervical dislocation; their pancreases were extracted, weighed, and the primary volume of the pancreases (V primary) was estimated using "immersion method" (18). The method of sectioning, processing, staining, and measurement of the sections was fully described by Noorafshan et. al (19). The fixative solution was neutral $4 \%$ buffered formaldehyde solution (supplier methanol, $\mathrm{pH}$ 6.9), and the incubation period lasted for 72 hours. After tissue processing, the degree of shrinkage $(\mathrm{d}(\mathrm{sh}))$ of the pancreas and the final pancreas volume were also measured according to the previously defined method (19). The $d(\mathrm{sh})$ was calculated according to the following formula:

$\mathrm{d}(\mathrm{sh})=1-(\mathrm{AP} / \mathrm{BP})^{1.5}$, as the AP is the area of each section after processing and the $\mathrm{BP}$ is the same area before processing.

Volume density $(\mathrm{Vv})$ of the pancreatic islets was estimated by point-counting method using a video microscopy system made up of a microscope (E-200, Nikon, Tokyo, Japan) connected to a video-camera, a computer, and a Microcator (MT-12, Heidenhain, Traunreut, Germany) (18). The microscopic field of each slide was selected in a systematic random method and analyzed by $340 \times$ magnification (Figure 1 ). The formula used to measure the $\mathrm{Vv}$ of the islets is as follows (18):

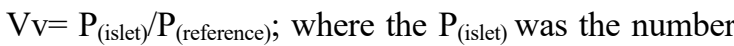
of points hitting the profiles of the islets and $\mathrm{P}_{\text {(reference) }}$ 
was the number of points hitting on the reference space (whole tissue).

The absolute volume (V) of the islets were also assessed according to the following formula (18):

$\mathrm{V}=\mathrm{Vv} \times \mathrm{V}_{(\text {primary })} \times(1-\mathrm{d}(\mathrm{sh}))$.
Using the "optical dissector" technique with a final magnification of $3400 \times$, the numerical density $(\mathrm{Nv})$ of the beta cells was determined using $20 \mu \mathrm{m}$ slides (Figure 2). Counting the cells was performed according to a method used by Gundersen et al. (20). The total number of the beta cells (N(beta)) was additionally estimated (18).

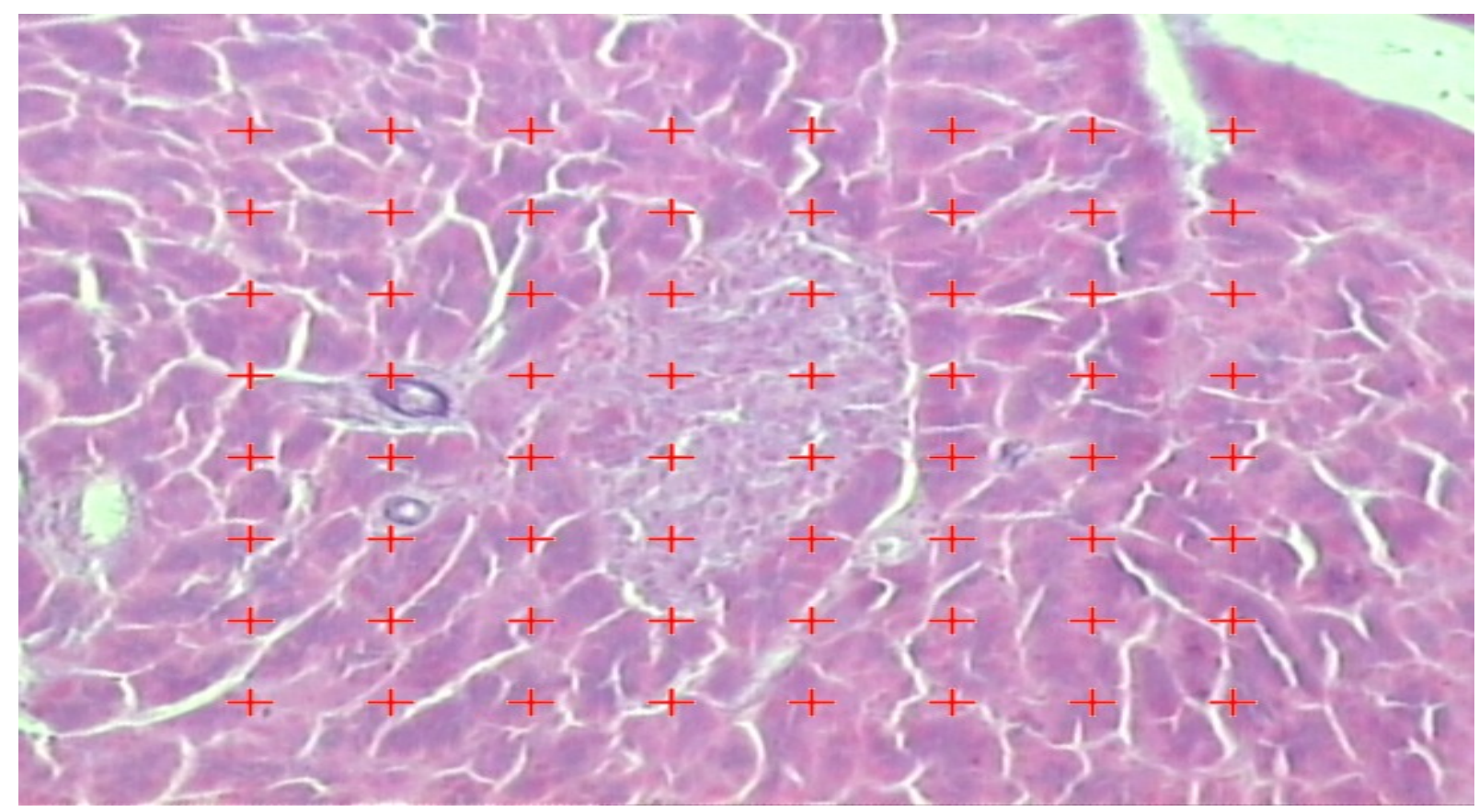

Figure 1. Volume density (Vv) of the pancreatic islets was estimated by the point-counting method by using a video microscopy system. The microscopic field of each slide was selected in a systematic random method and analyzed. The total number of points hitting the islets is counted and divided by the total number of points hitting the whole tissue. The crosses are counted only if the right upper corner of the cross hits the tissue (modified Aldehyde Fuchsin) $(340 \times)$.

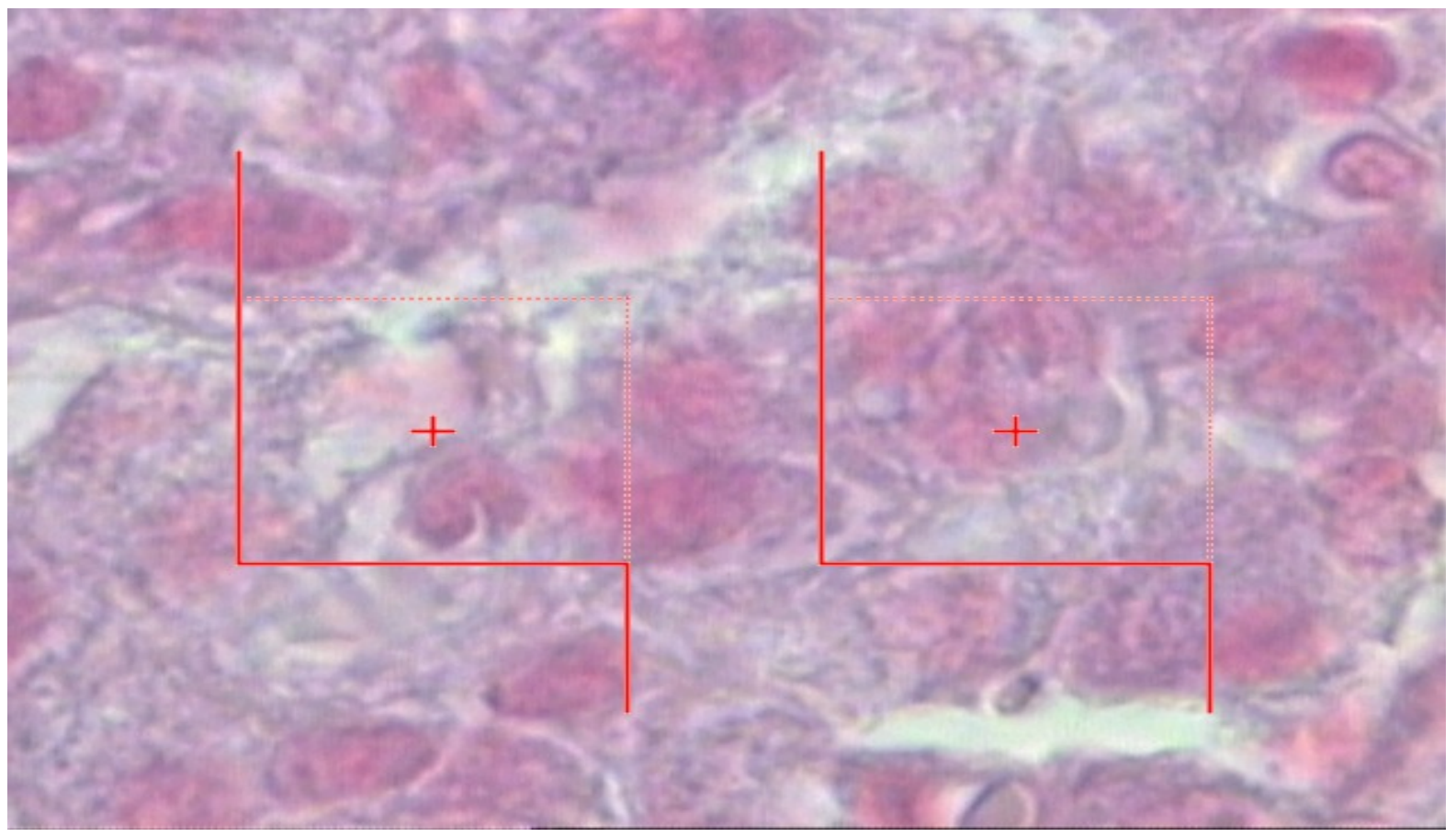

Figure 2. To estimate the numerical density (Nv) of the beta cells any cell that lied in the counting frame or touched the inclusion borders (red dotted lines) and did not touch the exclusion borders (continuous red lines) and come into maximal focus within the next traveling $5 \mu \mathrm{m}$ optical section (height of the dissector) are counted (modified Aldehyde Fuchsin) (3400×). 


\section{Ethical considerations}

All institutional and national guidelines for the care and use of laboratory animals were followed. Besides, the study protocol was approved by the IRB of the medical ethics committee of Shiraz University of medical sciences, Shiraz, Iran (Reg. No: 90-01-613948).

\section{Statistical analysis}

The measured volumes and counts were rendered into SPSS (version 21.0, SPSS Inc., Chicago, IL., USA). Descriptive analysis was used to compute the mean and standard deviation (SD). Kruskal-Wallis and MannWhitney $U$ tests were used for the non-parametric data analysis, and a P-value $\leq 0.05$ was considered as statistically significant.

\section{Results}

Our results demonstrated that there were no significant differences between the groups concerning body weight, pancreas weight, primary and the final volume of the pancreases as well as the degree of shrinkage (Table 1).

Table 1. Effects of Mellisa officinalis (MO) on STZ-induced diabetes in rats.

\begin{tabular}{|c|c|c|c|c|c|c|c|c|c|c|}
\hline \multirow[b]{2}{*}{ Groups } & \multicolumn{2}{|c|}{ Weight } & \multicolumn{3}{|c|}{ Pancreas volume } & \multicolumn{2}{|c|}{ Islets } & \multicolumn{2}{|c|}{ Beta cells } & \multirow{2}{*}{$\begin{array}{l}\text { Blood } \\
\text { Sugar } \\
(\mathrm{mg} / \mathrm{dL})\end{array}$} \\
\hline & $\begin{array}{l}\text { Body } \\
(\mathrm{g})\end{array}$ & $\begin{array}{c}\text { Pancreas } \\
(\mathrm{mg})\end{array}$ & $\begin{array}{c}\text { Primary } \\
\left(\mathrm{mm}^{3}\right)\end{array}$ & $\begin{array}{l}\text { Final } \\
\left(\mathrm{mm}^{3}\right)\end{array}$ & $\begin{array}{c}\text { Shrink } \\
(\%)\end{array}$ & $\begin{array}{l}\text { VV } \\
(\%)\end{array}$ & $\begin{array}{c}\text { Total } \\
\text { volume } \\
\left(\mathrm{mm}^{3}\right)\end{array}$ & $\begin{array}{c}\mathrm{Nv} \\
\left(\text { per } \mathrm{mm}^{3}\right)\end{array}$ & $\begin{array}{c}\text { Total } \\
\text { number } \\
\left(\times 10^{6}\right)\end{array}$ & \\
\hline \multirow{2}{*}{ C1 } & 221.87 & 860.41 & $830.31 \pm$ & 711.79 & 14.27 & 0.96 & 6.81 & 1933.38 & $1.16 \pm$ & 138.52 \\
\hline & \pm 9.16 & \pm 74.22 & 45.79 & \pm 33.7 & \pm 0.15 & \pm 0.91 & \pm 2.06 & $\pm 391.27^{*}$ & $0.39 *$ & \pm 41.23 \\
\hline \multirow{2}{*}{$\mathrm{C} 2$} & 209.43 & 872.39 & $918.21 \pm$ & 715.44 & 22.35 & 0.39 & 2.78 & 127.81 & $0.27 \pm$ & 721.33 \\
\hline & \pm 11.60 & \pm 97.24 & 82.13 & \pm 92.84 & $\pm 0.21 \dagger$ & $\pm 0.73 \dagger$ & $\pm 0.54 \dagger$ & $\pm 84.57 \dagger$ & $0.18 \dagger$ & $\pm 29.31 \dagger$ \\
\hline \multirow{2}{*}{ T1 } & 201.18 & 880.81 & $841.18 \pm$ & 613.42 & 26.21 & 0.66 & 4.05 & 586.27 & $0.97 \pm$ & 522.18 \\
\hline & \pm 7.22 & \pm 82.27 & 17.28 & \pm 64.17 & \pm 0.54 & $\pm 0.14 *$ & $\pm 0.90^{*}$ & $\pm 32.56^{*}$ & $0.85 *$ & $\pm 91.22 *$ \\
\hline \multirow{2}{*}{$\mathbf{T} 2$} & 198.45 & 849.19 & $832.75 \pm$ & 681.03 & 18.8 & 0.58 & 3.95 & 493.81 & $0.83 \pm$ & 484.38 \\
\hline & \pm 9.27 & \pm 38.71 & 49.91 & \pm 36.16 & \pm 1.54 & $\pm 0.13^{*}$ & $\pm 1.56^{*}$ & $\pm 139.39 *$ & $0.23 *$ & $\pm 81.51 *$ \\
\hline
\end{tabular}

Weights of the rats $(\mathrm{g})$ and their pancreases $(\mathrm{mg})$, primary and final volume of pancreases $\left(\mathrm{mm}^{3}\right)$, shrinkage ratio $(\%)$, volume density $(\mathrm{Vv} ; \%)$ and total volume of the pancreatic islets $\left(\mathrm{mm}^{3}\right)$, numerical density $\left(\mathrm{Nv}\right.$; per $\left.\mathrm{mm}^{3}\right)$ and the total number of beta cells $\left(\times 10^{6}\right)$ in each group: $\mathrm{C} 1$ as non-diabetics, C2 as not treated diabetics, T1 as diabetics with $150 \mathrm{mg} / \mathrm{kg} \mathrm{MO}$, and T2 as diabetic rats with $300 \mathrm{mg} / \mathrm{kg} \mathrm{MO}$ (n=12).

$* P \leq 0.05$ vs. C2 group

$\dagger P \leq 0.05$ vs. C1 group

Significant differences were presented between the two treatment groups and the untreated group (C2) regarding the volume density and total volume of the islets, numerical density, and population of the beta cells $(P<0.001)$. Treatment groups (T1 and T2) also had an increase of blood glucose, which was considerable compared to normal rats $(P<0.001)$, but significantly lower than that of the untreated $\mathrm{C} 2$ rats $(P=0.008)$.

\section{Discussion}

DM has become a certain concern for health care systems due to its significant influence on health, quality of life, and life expectancy. More than 300 medicinal species have been introduced in order to manage DM, such as Olea europaea, Momordica charantia, Amygdalus scoparia, Allium sativum, Anethum graveolen, Cinnamomum verum, Securigera securidaca, Citrullus colocynthis, Arctium lappa, and Zataria multiflora $(4,21)$. Commonly, it is believed that herbal medicines might have fewer side effects and complications than conventional therapies as they are naturally produced. Moreover, these agents are considered among the main components of complementary and alternative medicine (CAM) (22).

To the best of our knowledge, our investigation is the first study that evaluates the effects of MO in STZinduced diabetes in rats using stereological methods.
Our results showed that MO administration for diabetic rats could improve beta cell functions by increasing the volume density and total volume of the pancreatic islets and also lowering the blood glucose. Moreover, the numerical density and population of the beta cells were also increased after MO administration. These results are consistent with the findings of an earlier investigation that showed the destruction of the pancreatic islets could be prevented by administrating MO in STZ-induced diabetic animal models (23).

While the present study also showed MO supplementation could significantly lower the serum glucose in STZ-induced diabetic rats, the blood glucose had not been reverted back to the normal levels. Consistently, both in vitro and in vivo studies demonstrated that MO supplementation could have hypoglycemic effects $(16,24-27)$. It was shown that the agent can stimulate cellular glucose consumption and prevent the lipid accumulation into cells (28). Administration of MO increased serum insulin and decreased oxidative stress via various pathways (16, 28). In another study, the diabetic rats that were treated with MO extract had restored their euglycemic state and lost body weight (15). A clinical trial found MO extract supplementation could significantly improve fasting blood glucose and hemoglobin A1C in diabetic patients (29). Moreover, MO extract had 
beneficial effects in terms of increasing the apolipoprotein A-I and lowering the triglyceride levels in diabetic patients without any serious side effects $(30,31)$.

This study had several limitations to be mentioned. The application of MO extract was started 1 week before diabetes induction; however, the narrow lifespan of the rats after STZ-diabetic induction has limited the follow-up duration of the rats. Assessing blood glucose using glucometer by obtaining blood from the tail vein could cause increased stress to the rats leading to increased blood sugar. Moreover, we did not evaluate the oxidative biomarkers and inflammatory markers that could be beneficial.

\section{Conclusion}

Mellisa officinalis hydroalcoholic extract could be used as an alternative treatment or a supplement for $\mathrm{DM}$ as it showed promising effects in terms of preventing damage to pancreatic islets and beta cells. However, further experiments, as well as clinical trials, are still suggested to examine the beneficial effects and possible adverse effects of MO in diabetes.

\section{Acknowledgments}

The authors thank all those who helped them writing this article.

\section{Ethical considerations}

Ethical issues (Including plagiarism, informed consent, misconduct, data fabrication and/or falsification, double publication and/or submission, redundancy, etc.) have been completely observed by the authors.

\section{Funding and support}

This research resulted from an independent research without receiving any financial support.

\section{Conflict of Interest}

Authors declared no conflict of interest.

\section{References}

1. Wild S, Roglic G, Green A, Sicree R, King H. Global prevalence of diabetes: estimates for the year 2000 and projections for 2030. Diabetes Care. 2004;27(5):1047-53. [DOI:10.2337/diacare.27.5.1047]

2. Giugliano D, Ceriello A, Paolisso G. Oxidative stress and diabetic vascular complications. Diabetes Care. 1996;19(3):257-67. [DOI:10.2337/diacare.19.3.257]

3. Montonen J, Knekt P, Järvinen R, Reunanen A. Dietary antioxidant intake and risk of type 2 diabetes. Diabetes Care. 2004;27(2):362. [DOI:10.2337/diacare.27.2.362]

4. Bastaki A. Diabetes mellitus and its treatment. Int J Diabet Metab. 2005;13(3):111. [DOI:10.1159/000497580]

5. Dey L, Attele AS, Yuan C-S. Alternative therapies for type 2 diabetes. Alternat Med Rev. 2002;7(1):45-58.

6. Knekt P, Reunanen A, Marniemi J, Leino A, Aromaa A. Low vitamin E status is a potential risk factor for insulin-dependent diabetes mellitus. J Inter Med. 1999;245(1):99-102. [DOI:10.1046/j.1365-2796.1999.00416.x]

7. Abahusain M, Wright J, Dickerson J, De Vol E. Retinol, $\alpha$-tocopherol and carotenoids in diabetes. Europ J Clin Nutri. 1999;53(8):630. [DOI:10.1038/sj.ejen.1600825]

8. Polidori M, Mecocci P, Stahl W, et al. Plasma levels of lipophilic antioxidants in very old patients with type 2 diabetes. Diabet Metab Res Rev. 2000;16(1):15-9. https://doi.org/10.1002/(SICI)15207560(200001/02)16:1<15::AID-

DMRR71>3.0.CO;2-B

[DOI:10.1002/(SICI)15207560(200001/02)16:13.0.CO;2-B]

9. Ford ES, Mokdad AH. Fruit and vegetable consumption and diabetes mellitus incidence among US adults. Prevent Med. 2001;32(1):33-9. [DOI:10.1006/pmed.2000.0772]

10. Bailey CJ, Day C. Traditional plant medicines as treatments for diabetes. Diabetes Care. 1989;12(8):553-64.

[DOI:10.2337/diacare.12.8.553]

11. Moacă EA, Farcaş C, Ghiţu A, et al. A Comparative Study of Melissa officinalis Leaves and Stems Ethanolic Extracts in terms of Antioxidant, Cytotoxic, and Antiproliferative Potential. Evid Based Complement Alternat Med. 2018;2018:7860456. [DOI:10.1155/2018/7860456]

12. Basar SN, Zaman R. An overview of badranjboya (Melissa officinalis). Int Res J Biol Sci. 2013;2(12):107-9.

13. Sadraei H, Ghannadi A, Malekshahi K. Relaxant effect of essential oil of Melissa officinalis and citral on rat ileum contractions. Fitoterapia. 2003;74(5):445-52. [DOI:10.1016/S0367326X(03)00109-6]

14. Miraj S, Rafieian K, Kiani S. Melissa officinalis L: A Review study with an antioxidant prospective. J Evid Based Complement Alternat Med. 2016;22(3):385-94. [DOI:10.1177/2156587216663433] 
15. Hasanein P, Riahi H. Antinociceptive and antihyperglycemic effects of Melissa officinalis essential oil in an experimental model of diabetes. Med Principles Practice. 2015;24(1):47-52. [DOI:10.1159/000368755]

16. Chung MJ, Cho S-Y, Bhuiyan MJH, Kim KH, Lee S-J. Anti-diabetic effects of lemon balm (Melissa officinalis) essential oil on glucose- and lipid-regulating enzymes in type 2 diabetic mice. $\mathrm{Br} \quad \mathrm{J} \quad$ Nutr. 2010;104(2):180-8. [DOI:10.1017/S0007114510001765]

17. Herodež ŠS, Hadolin M, Škerget M, Knez Ž. Solvent extraction study of antioxidants from Balm (Melissa officinalis L.) leaves. Food Chem. 2003;80(2):275-82.

[DOI:10.1016/S03088146(02)00382-5]

18. Noorafshan A, Ebrahimi S, Esmaeilzadeh E, Arabzadeh H, Bahmani-Jahromi M, AshkaniEsfahani S. Effects of Arnebia Euchroma extract on streptozotocin induced diabetes in rats: A stereological study. Acta Endocrinologica (Bucharest). 2017;13(3):272.

[DOI:10.4183/aeb.2017.272]

19. Noorafshan A, Hoseini L, Karbalay-Doust S, Nadimi E. A simple stereological method for estimating the number and the volume of the pancreatic beta cells. JOP J Pancreas. 2012;13(4):427-32.

20. Gundersen H, Bagger P, Bendtsen T, et al. The new stereological tools: disector, fractionator, nucleator and point sampled intercepts and their use in pathological research and diagnosis. Apmis. 1988;96(7-12):857-81. [DOI:10.1111/j.1699-0463.1988.tb00954.x]

21. Baharvand-Ahmadi B, Bahmani M, Tajeddini P, Naghdi N, Rafieian-Kopaei M. An ethnomedicinal study of medicinal plants used for the treatment of diabetes. J Nephropathol. 2016;5(1):44-50. [DOI:10.15171/jnp.2016.08]

22. Gordon JS. Alternative medicine and the family physician. Am Family Physician. 1996;54(7):2205-12, 18-20.

23. Shin Y, Lee D, Ahn J, Lee M, Shin SS, Yoon M. The herbal extract ALS-L1023 from Melissa officinalis reduces weight gain, elevated glucose levels and $\beta$-cell loss in Otsuka Long-Evans Tokushima fatty rats. J Ethnopharmacol. 2020;113360. Epub ahead of print. [DOI:10.1016/i.jep.2020.113360]
24. Weidner C, Wowro SJ, Freiwald A, et al. Lemon balm extract causes potent antihyperglycemic and antihyperlipidemic effects in insulin-resistant obese mice. Mol Nutr Food Res . 2014;58(4):9037 [DOI:10.1002/mnfr.201300477]

25. Zeraatpishe A, Oryan S, Bagheri $\mathrm{MH}$, et al. Effects of Melissa officinalis L. on oxidative status and DNA damage in subjects exposed to long-term low-dose ionizing radiation. Toxicol Ind Health. 2011;27(3):205-12. [DOI:10.1177/0748233710383889]

26. Martins EN, Pessano NT, Leal L, et al. Protective effect of Melissa officinalis aqueous extract against Mn-induced oxidative stress in chronically exposed mice. Brain Res Bull .2012;87(1):74-9.

[DOI:10.1016/j.brainresbull.2011.10.003]

27. Shakeri A, Sahebkar A, Javadi B. Melissa officinalis L. - A review of its traditional uses, phytochemistry and pharmacology. J Ethnopharmacol. 2016;188:204-28. [DOI:10.1016/j.jep.2016.05.010]

28. Yen HF, Hsieh CT, Hsieh TJ, Chang FR, Wang CK. In vitro anti-diabetic effect and chemical component analysis of 29 essential oils products. J Food Drug Analysis. 2015;23(1):124-9. [DOI:10.1016/i.jfda.2014.02.004]

29. Asadi A, Shidfar F, Safari M, et al. Efficacy of Melissa officinalis L. (lemon balm) extract on glycemic control and cardiovascular risk factors in individuals with type 2 diabetes: A randomized, double-blind, clinical trial. Phytother Res. 2019;33(3):651-9. [DOI:10.1002/ptr.6254]

30. Neda N, Alireza E, Alipasha M, et al. The effects of a Melissa officinalis L. based product on metabolic parameters in patients with type 2 diabetes mellitus: A randomized double-blinded controlled clinical trial. J Complement Integ Med. 2019;16(3):20180088. [DOI:10.1515/jcim-20180088]

31. Asadi A, Shidfar F, Safari M, et al. Safety and efficacy of Melissa officinalis (lemon balm) on ApoA-I, Apo B, lipid ratio and ICAM-1 in type 2 diabetes patients: A randomized, double-blinded clinical trial. Complement Ther Med. 2018;40:83-8. [DOI:10.1016/j.ctim.2018.07.015] 


\section{How to Cite This Article:}

Ashkani-Esfahani S, Ebrahimi A, Bahmani-Jahromi M, Nadimi E, Arabzadeh H, Jalalpour M H, et al . The Effect of Melissa officinalis Extract on Streptozotocin-Induced Diabetes in Rats: A Stereological Study on Pancreatic Islets and Beta-cells. J Adv Med Biomed Res. 2020; 29 (132) :34-40

\section{Download citation:}

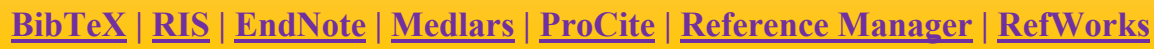

\section{Send citation to:}

(3) Mendeley 2 Zotero (i)efWorks RefWorks 